\title{
Balkanologie
}

Balkanologie Revue d'études pluridisciplinaires

Vol. II, nº 2 | 1998

Volume II Numéro 2

\section{Kubli (Olivier Ladislav), Du nationalisme yougoslave aux nationalismes post-yougoslaves}

Paris : L'Harmattan, 1998, 252 p. [Bibliogr.].

\section{Patrick Michels}

\section{CpenEdition}

\section{Journals}

Édition électronique

URL : http://journals.openedition.org/balkanologie/275

DOI : 10.4000/balkanologie. 275

ISSN : 1965-0582

\section{Éditeur}

Association française d'études sur les Balkans (Afebalk)

Édition imprimée

Date de publication : 1 décembre 1998

ISSN : 1279-7952

\section{Référence électronique}

Patrick Michels, « Kubli (Olivier Ladislav), Du nationalisme yougoslave aux nationalismes post-

yougoslaves », Balkanologie [En ligne], Vol. II, n² 2 | 1998, mis en ligne le 03 juin 2008, consulté le 17

décembre 2020. URL : http://journals.openedition.org/balkanologie/275 ; DOI : https://doi.org/

10.4000/balkanologie.275

Ce document a été généré automatiquement le 17 décembre 2020.

(c) Tous droits réservés 


\section{Kubli (Olivier Ladislav), Du nationalisme yougoslave aux nationalismes post-yougoslaves}

Paris : L'Harmattan, 1998, 252 p. [Bibliogr.].

\section{Patrick Michels}

\section{RÉFÉRENCE}

Kubli (Olivier Ladislav), Du nationalisme yougoslave aux nationalismes post-yougoslaves, Paris : L’Harmattan, 1998, 252 p. [Bibliogr.].

1 O. Kubli propose une réflexion théorique sur la nation et le nationalisme qu'il exemplifie par l'éclatement de la Yougoslavie. Éloigné des clichés les plus communs qu'on a pu trouver dans nombre d'ouvrages publiés depuis la fin de l'Union des Slaves du Sud, son travail contient malheureusement quelques défauts qui réduisent la portée de son labeur.

2 La première partie consiste en un rappel des théories de la nation qui ont été développées. L'auteur souligne combien la nation est fonction des conditions sociohistoriques de sa production, que si elle est bien une construction élitiste, il n'en faut pas moins tenir compte de la potentialité de diffusion de cette construction; le nationalisme étant l'activité politique consistant à construire une nation, qui a, d'ailleurs, plus de chances d'être bien accueilli par la population visée si la société se trouve en période de changements importants.

3 Néanmoins, alors que la thématique de son livre porte sur une partie de l'Europe de l'est, l'auteur ne fait aucune référence aux auteurs ayant travaillé spécifiquement sur les nationalismes est-européens ${ }^{1}$, mais pratique une utilisation fine des récents travaux historiques ou sociologiques sur la nation.

4 La deuxième partie de l'ouvrage est consacrée au développement du nationalisme en Yougoslavie. Elle débute par une étude de l'évolution fédérale de la Yougoslavie d'où 
est, également, absente une référence majeure pour qui se penche sur les métamorphoses fédérales yougoslaves et l'évolution du discours du $\mathrm{PCY}^{2}$. On est surpris d'apprendre que la Constitution de 1946 faisait de la Voïvodine et du Kosovo deux provinces autonomes qui ne semblent être rattachées à aucune République, alors qu'elles étaient bien évidemment rattachées à la République Populaire de Serbie. L'auteur semble également méconnaître le fait que le droit d'autodétermination affirmé dans la première Constitution yougoslave d'après-guerre était considéré avoir été exercé lors de la seconde création en 1945 (ce qu'on trouve pourtant dans l'étude d'Aleksa Djilas cité dans la bibliographie). De plus, O. Kubli ne donne aucun renseignement sur la signification et l'usage de "narod" en Yougoslavie, alors qu'il faut, comme il l'a précisé en introduction, ne pas oblitérer les définitions intégrées par les acteurs en gardant toujours en mémoire leur caractère subjectif.

Contrairement à ce que donne à penser le titre de l'ouvrage, $\mathrm{O}$. Kubli ne propose pas une étude des nationalismes yougoslaves, mais des nationalismes croate et serbe, ce que, bien entendu, il légitime. D'une part, la Yougoslavie étant essentiellement un espace linguistique serbo-croate, les nationalismes slovène, macédonien et albanais n'ont pas à être évoqués. D'autre part, les Monténégrins représentant une "sousdivision des Serbes", leurs nationalismes (puisqu'ils ont développé plusieurs revendications identitaires et sont sujets de bien d'autres) ne seront pas non plus abordés, ni non plus celui des Musulmans qui ont subi l'éclatement yougoslave. Alors que l'auteur a, dans sa première partie, insisté sur les interactions sociales productrices de nationalisme, il élimine de son exemple quelques éléments qui en sont pourtant partie prenante. De plus, son étude des nationalismes croate et serbe se termine aux débuts des guerres yougoslaves, c'est-à-dire après les élections de 1990 dans lesquelles les nationalistes bosniaques croates, musulmans et serbes s'étaient alliés. On ne comprend pas alors l'utilité de sa remarque sur le référendum : «le référendum n'est en aucun cas une solution (...). La volonté commune est impossible à déterminer, puisque c'est l'enjeu même de la lutte des nationalistes: que faire lorsque seulement une partie d'une population ne confirme pas (ou plus) le "plébiscite de tous les jours" ?» (p. 76). Enfin, la seule référence en serbo-croate est loin d'être majeure dans toute la production dans cette langue sur fédéralisme et le nationalisme en Yougoslavie.

6 Toutefois, l'étude des nationalismes croate et serbe est intéressante et rectifie bien des erreurs qui ont été affirmées depuis huit ans, même si l'oblitération des autres nationalismes empêche de saisir toutes les interactions qui se sont réalisées. L'auteur montre bien «comment les pouvoirs républicains vont récupérer et canaliser [le] mécontentement économique sur la voie de la haine interethnique, sans pour autant améliorer la situation matérielle de la population, bien au contraire » (p. 172). Ainsi, en 1987, Slobodan Milošević réalise l'accaparement nationaliste qui lui permettra de rester au pouvoir (pouvant tirer profit du désemparement serbe au Kosovo et du soutien de nombreux intellectuels), avant de tenir un discours anti-yougoslave identique à celui des nationalistes croates (leur long silence étant une conséquence des purges de 1971). La différence entre les dirigeants nationalistes élus en 1990 tient à ce que «Milošević n'a fait que s'octroyer des théories formulées par d'autres, [tandis que] Franjo Tudjman [a développé] lui-même les thèses nationalistes croates » (p. 212). 
7 En conclusion, O. Kubli souligne que le «si le nationalisme a conservé tous les travers du communisme, il a exclu les aspects positifs ». Sauf à s'en débarrasser, les restes yougoslaves ont un avenir qui semble bien sombre devant eux.

\section{NOTES}

1. Comme, par exemple, Krejči (Jaroslav), Velímský (Vítìzslav), Ethnic and Political Nations in Europe, New York : St Martin Press, 1981 ou Klein (George), Renan (Milan J.), eds., The Politics of Ethnicity in Eastern Europe, Boulder : East European Monographs, 1981.

2. Ramet (Pedro), Nationalism and communism in Yugoslavia, 1963-1983, Bloomington: Indiana University Press, 1984 ou la seconde édition, Ramet (Sabrina Petra), Nationalism and communism in Yugoslavia, 1962-1991, Bloomington : Indiana University Press, 1993 